\title{
Derecho de autor y diseño industrial, ¿cómo dibujar una línea? La protección en Colombia de las obras de arte aplicado a la industria ${ }^{*}$
}

\author{
Copyright and Industrial Design, How a Line Should be Drawn? Works \\ of Applied Arts, its Protection in Colombia \\ Direito de autor e desenho industrial, como desenhar uma linha? \\ A proteção na Colômbia das obras de arte aplicado à indústria
}

\author{
DaVID Felipe ÁlVAREZ AmÉZQUitA*
}

FECHA DE RECEPCIÓN: 17 DE AGOSTO DE 2014. FECHA DE ACEPTACIÓN: 3 DE DICIEMBRE DE 2014

Doi: dx.doi.org/10.12804/esj17.02.2015.02

Para citar este artículo: Álvarez Amézquita, D. F., (2015). Derecho de autor y diseño industrial, ¿cómo dibujar una línea? La protección en Colombia de las obras de arte aplicado a la industria. Estudios Socio-Jurídicos, 17(2), 199-232. Doi: dx.doi. org/10.12804/esj 17.02.2015.02

\section{RESUMEN}

El artículo discute las tres diferentes aproximaciones que en el derecho comparado se han desarrollado para el caso de las obras de arte aplicadas a la industria como una zona gris entre el derecho de autor y el derecho de propiedad industrial. Se enfoca únicamente en el caso del diseño industrial y su posible protección simultánea, a través del derecho de autor. Se propone que la legislación colombiana, junto con la normatividad comunitaria andina, debería acoger el sistema de acumulación parcial de protección del diseño industrial como obra protegida por el derecho de autor, siempre que tales diseños cumplan con los requisitos mínimos de protección del derecho de autor y particulares de las obras de arte y de arte aplicado.

Palabras clave: Derecho de autor, diseño industrial, propiedad industrial, zonas grises, derecho comparado.

* Artículo de reflexión desarrollado por el autor como actividad de investigación al interior del Grupo de Estudios en Derecho Público General de la Universidad del Tolima, en su calidad de Asistente de Docencia e Investigación y Becario de Doctorado.

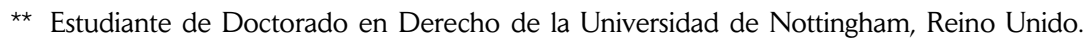
Magíster en Historia y Abogado de la Universidad Nacional de Colombia, especialista en Propiedad Intelectual de la Universidad Externado de Colombia. Asistente de Docencia e Investigación de la Facultad de Ciencias Humanas y Artes de la Universidad del Tolima. Becario de doctorado de la Universidad del Tolima. Becario de Doctorado de Colciencias. Correo electrónico: dfalvareza@ut.edu.co 


\section{ABSTRACT}

As works of applied arts have been situated normally at the grey area between copyright and industrial property, this article discusses three different approaches about how they should be protected. It particularly focuses on the case of industrial designs which might be considered as copyrighted works. Subject to the fulfilment of copyright criterions and particularly the requisites for works of art and for the work of applied arts, the article proposes that Colombian and Andean Communitarian Law should embrace the partial accumulation system of protection for such creations.

Key words: Copyright, industrial designs, industrial property, grey areas, comparative law.

\section{RESUMO}

O artigo discute a três diferentes aproximações que no direito comparado se têm desenvolvido para o caso das obras de arte aplicado à indústria como uma zona cinzenta entre o direito de autor e o direito de propriedade industrial. Enfoca-se unicamente no caso do desenho industrial e sua possível proteção simultânea através do direito de autor. Propõe-se que a legislação colombiana junto com a normatividade comunitária andina deveria acolher o sistema de acumulação parcial de proteção do desenho industrial como obra protegida pelo direito de autor, sempre que tais desenhos cumpram com os requisitos mínimos de proteção do direito de autor e particulares das obras de arte e arte aplicada.

Palavras- chave: Direito de autor, Desenho Industrial, Propriedade Industrial, Zonas Cinzentas, Direito Comparado. 
En algunos casos, dos de las principales ramas de la propiedad intelectual -el derecho de autor y la propiedad industrial- se tocan en sus campos de protección. ${ }^{1}$ Es lo que la doctrina ha dado en llamar zonas grises de la propiedad intelectual. En esta zona se ubican las denominadas obras de arte aplicadas a la industria, es decir, aquellos casos en los que una obra de arte puede tener una aplicación industrial. Uno de estos casos se produce en lo relativo al diseño industrial y la posible aplicación de las normas de derecho de autor a este tipo de creaciones. El presente artículo busca proponer una línea de interpretación para determinar cuándo se puede acumular la protección de los dos sistemas.

$\mathrm{Al}$ acumularse el derecho de autor con el derecho concedido por las normas relativas a los diseños industriales, se produce un efecto de doble protección que puede favorecer ampliamente a la industria asociada a este tipo de creaciones. Sin embargo, existe el riesgo de que objetos que no se encuentran en el campo de la protección del derecho de autor pero sí en el del diseño industrial, se beneficien ilegítimamente de esta zona gris. ${ }^{2} \mathrm{La}$ anterior manifestación da cuenta de una posición respecto de la discusión que se ha desarrollado sobre este tema, pues supone que es posible que haya objetos susceptibles de ser protegidos por la propiedad industrial como diseños que no podrían ser protegidos por el derecho de autor.

1 El artículo 2 del Convenio que establece la Organización Mundial de la Propiedad Intelectual, firmado en Estocolmo el 14 de julio de 1967 y ratificado en Colombia mediante la Ley n. 46 de 1979 (Congreso de la República de Colombia, 1979), señala que la propiedad intelectual hace referencia a los derechos relativos a las obras literarias, artísticas y científicas (lo que comprende el derecho de autor en sentido estricto), a las interpretaciones de los artistas intérpretes y a las ejecuciones de los artistas ejecutantes, a los fonogramas y a las emisiones de radiodifusión (referido a los derechos conexos al derecho de autor), a las invenciones en todos los campos de la actividad humana, a los descubrimientos científicos, a los dibujos y modelos industriales, a las marcas de fábrica, de comercio y de servicio, así como a los nombres y denominaciones comerciales (lo que en términos generales se conoce como la propiedad industrial), a la protección contra la competencia desleal y todos los demás derechos relativos a la actividad intelectual en los terrenos industrial, científico, literario y artístico.

2 En otro espacio se ha publicado un estudio realizado por el autor en relación con las políticas públicas en materia de diseño industrial para Colombia. Uno de los aspectos allí señalados es el relacionado con la seguridad jurídica y la correcta administración de los derechos de propiedad intelectual relacionados con el diseño. Uno de tales aspectos en términos de políticas públicas es el que da lugar a este artículo; se trata de no generar ventajas competitivas desproporcionadas en el campo del comercio, por medio del uso indebido de la propiedad intelectual. Al efecto ver: Álvarez Amézquita, D. F., (2011). Elementos para la consideración de la propiedad intelectual en una política de diseño. Acto, 11(1), pp. 34-41. 
$\mathrm{Al}$ respecto, en la doctrina se han desarrollado fundamentalmente tres posibilidades (Reichman, 1983, p. 1213), la llamada unidad del arte, derivada del derecho francés, donde no se separa aquello que puede ser protegido por el derecho de autor y lo que se protege como diseño industrial; el sistema de acumulación parcial, en el que algunos elementos pueden compartir la protección de las dos disciplinas; y, finalmente, el sistema de separación, en el cual si la obra tiene una función industrial no puede ser protegida por el derecho de autor.

Colombia, hasta la adopción de la Decisión Andina 351 de 1993 (Comisión del Acuerdo de Cartagena, 1993) adoptaba el sistema de separabilidad por medio del inciso segundo del artículo 6 de la Ley 23 de 1982, que señala (Congreso de la República de Colombia, 1982): "Las obras de arte aplicadas a la industria sólo son protegidas en la medida en que su valor artístico pueda ser separado del carácter industrial del objeto u objetos en las que ellas pueden ser aplicadas" La introducción de la norma andina suspendió esta disposición al señalar que la obra de arte aplicado es protegida por el derecho de autor (artículo 4, literal j.) y que la misma comprende una "creación artística con funciones utilitarias o incorporada en un artículo útil, ya sea una obra de artesanía o producida en escala industrial" (artículo 3).

Este cambio puede significar el tránsito de la legislación a un sistema de acumulación plena (unidad del arte) o uno de acumulación parcial. Lo anterior debido a que, aunque es evidente que el criterio de separabilidad no es aplicable en el marco de la norma andina, no es completamente claro que se haya adoptado la posición completamente opuesta, es decir, el de acumulación plena. Este escrito pretende demostrar por medio del análisis de la doctrina internacional en la materia y su comparación con la normatividad nacional y comunitaria, así como con la jurisprudencia comunitaria andina más reciente, que la norma andina adopta la posición intermedia de una acumulación parcial y no el de la unidad del arte.

La relevancia de esta distinción entre acumulación parcial y acumulación plena radica en las implicaciones que cada sistema puede tener. Para el efecto de la explicación se puede examinar comparativamente, y sin un ánimo exhaustivo, las diferencias básicas que los dos sistemas presentan de conformidad a la legislación andina aplicable (tabla 1) (Decisión Andina 351 de 1993 para el derecho de autor y Decisión Andina 486 de 2000 para los diseños industriales). 
Tabla 1. Comparación entre derecho de autor y diseño industrial

\begin{tabular}{|l|l|l|}
\hline \multicolumn{1}{|c|}{ Derecho de autor } & \multicolumn{1}{c|}{ Diseño Industrial } \\
\hline Formalidades & $\begin{array}{l}\text { No formalidades, protección } \\
\text { automática. }\end{array}$ & $\begin{array}{l}\text { Registro, pago de tasas, sujeto a concesión } \\
\text { por parte de la oficina nacional competente. }\end{array}$ \\
\hline $\begin{array}{l}\text { Plazo de } \\
\text { protección }\end{array}$ & $\begin{array}{l}\text { jo años mínimo, contados bien } \\
\text { desde la primera publicación de la } \\
\text { obra, si el titular es una persona ju- } \\
\text { rídica o desde la muerte del autor. }\end{array}$ & $\begin{array}{l}10 \text { años contados desde la solicitud del } \\
\text { registro. }\end{array}$ \\
\hline $\begin{array}{l}\text { Derechos } \\
\text { concedidos }\end{array}$ & $\begin{array}{l}\text { Derechos patrimoniales para con- } \\
\text { trolar cualquier forma de explota- } \\
\text { ción de obra. } \\
\text { Derechos morales para proteger la } \\
\text { relación del autor con su obra. }\end{array}$ & $\begin{array}{l}\text { Derechos de carácter económico para impedir } \\
\text { la explotación del diseño, lo que implica su } \\
\text { fabricación, importación, oferta, introducción } \\
\text { en el comercio o utilización comercial de pro- } \\
\text { ductos que lo incorporen o lo reproduzcan. }\end{array}$ \\
\hline
\end{tabular}

Fuente: elaboración propia.

La ventaja que otorga la protección del derecho de autor por encima del diseño industrial, hace que el primero sea seductor en el ámbito del comercio. Si se toma, por ejemplo, el caso de una botella de vino desarrollada para distinguir el producto del de otros competidores (ilustración 1), al adoptar la acumulación plena para este caso, la consecuencia es que dicha botella recibiría el pleno de las dos protecciones. Si, por el contrario, se adopta el criterio ya superado de separabilidad, solo si el arte en la botella puede separarse de la botella misma, habría protección por derecho de autor. Si se aplica el criterio de acumulación parcial, como se sostiene en este artículo, se debe examinar si la botella en si accede al campo de lo artístico o no para ser depositaria de la protección del derecho de autor.

Aplicando el cuadro anterior a este ejemplo, se llega al siguiente análisis: la empresa productora y comercializadora del vino tendría una amplia ventaja para excluir el uso de la botella durante 50 años mínimo respecto de sus competidores, en el caso de la acumulación plena, o en el caso de la aplicación del criterio de separabilidad, probablemente su protección se limitaría a la eventualmente concedida por el diseño industrial de 10 años desde la solicitud del registro. En el criterio de acumulación parcial, la pregunta se torna cualitativa, ¿qué hace que la botella sea una obra de arte? Si la respuesta es positiva, como por ejemplo, en las famosas botellas 


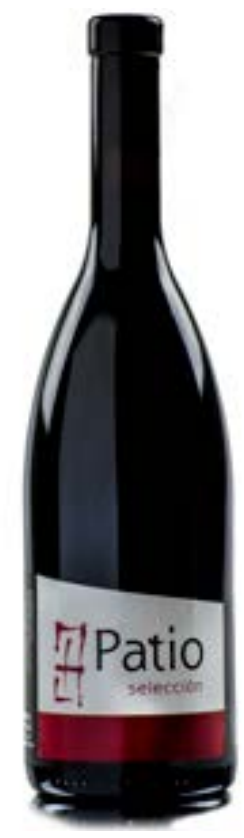

Ilustración 1. Botella de Vino Patio Selección

Fuente: (Israel, 2014).

creadas por Salvador Daliß estas recibirían plena protección por derecho de autor, pero si su forma es meramente creada para distinguirla de sus competidores, no habría tal protección por vía del derecho de autor. Estos son, claramente, ejemplos extremos con una utilidad meramente didáctica.

El lector puede estar pensando ahora que el problema radica en la naturaleza del Arte y de definir qué es Arte, y que tal pregunta es ajena al derecho, con lo cual se coincide. Pero ello no excluye que dada la legislación existente, se requiera establecer algún parámetro para, como se insinúa en el título, se pueda dibujar una línea entre los dos sistemas de protección. Si la legislación andina no estableciera el carácter artístico de la creación susceptible de protección como obra de arte aplicado, la discusión estaría zanjada, pero ello no es así.

3 Ejemplos de estas botellas se pueden encontrar en el sitio web: http://www.parfums-salvadordali.com/es/. Un ejemplo puede ser la botella "Itislove-Intense", al efecto ver: Dalí, S. (2014). Itislove-Intense. Recuperado el 16 de marzo de 2014, de shop.salvador-dali.org: http://shop.salvadordali.org/es/ 


\section{La obra y los requisitos de protección en relación con el diseño}

La definición de la obra como el objeto de protección del derecho de autor no es simple, pues está asociada a una de las principales formas de libertad humana: la creatividad. En el campo del derecho, el alcance del concepto de obra es relevante en la medida en que ello determina qué cosas son protegidas por el derecho de autor y cuáles no.

No es posible señalar de manera exhaustiva aquello que puede ser definido como obra, pues ello sería contrario a su propia naturaleza. La obra es definida en términos generales como toda creación intelectual de naturaleza literaria o artística susceptible de ser reproducida o divulgada en cualquier forma. ${ }^{4}$ De allí que las normas relativas al derecho de autor en el ámbito internacional y, subsecuentemente, las normas nacionales y supranacionales sobre la materia hayan tratado de establecer un marco que le permita al operador jurídico establecer en qué casos existe o no una obra. Derivados de estas normas, se han precisado algunos criterios de protección que ayudan a resolver esta inquietud (Lipszyc, 1993, p. 65), (Vega Jaramillo, 2010, pp. 16,17). Dichos criterios se pueden resumir de la siguiente manera:

- La originalidad: este es quizá uno de los criterios más importantes que señala el derecho de autor, pues hace alusión, precisamente, a la creación misma y a su naturaleza, la cual debe ser original. Entendemos por original aquella creación que se diferencia de otras de su misma especie o género, pues muestran el aporte individual del autor que las ha efectuado y permite entender que una no es reproducción de otra. La originalidad se entiende en el campo creativo, en el aporte creativo del autor.

4 El Glosario de la OMPI de Derecho de Autor y Derechos Conexos de 1980 (Boytha, 1980, p. 262) y la Guía y Glosario de la OMPI (Ficsor, 2003, p. 295) coinciden en la naturaleza creativa original que enmarca el concepto. En la legislación andina, el concepto de obra es establecido por el artículo 3 de la Decisión 351 de 1993: "Toda creación intelectual original de naturaleza artística, científica o literaria, susceptible de ser divulgada o reproducida en cualquier forma." (Comisión del Acuerdo de Cartagena, 1993). 
- La no protección de las ideas: en efecto, el derecho de autor al referirse a las obras entiende que las meras ideas, conceptos o métodos, no pueden ser objeto de protección, solo lo será la forma en que la idea se concreta en una obra.

- La ausencia de formalidades: gracias a este principio, el derecho de autor está llamado a proteger las obras de manera automática, sin depender de registro o autorización gubernativa o judicial alguna, la protección de una obra por el derecho de autor existe por el hecho mismo de la creación.

- La ausencia de calificación en cuanto al mérito o valor artístico, o el destino de la obra: el derecho de autor también busca ser de naturaleza objetiva, así que en lo que se respecta a la obra, esta debe ser original, pero no requiere que tenga algún grado de valor artístico o algún mérito, ya que tales criterios residen en la subjetividad, lo que genera una incertidumbre que repele el derecho. Así mismo, el derecho de autor no atiende al destino de la obra, no le importa con qué objeto fue creada, si con fin meramente contemplativo, como una herramienta, o con cualquier otra destinación.

- Independencia del soporte material: el derecho de autor protege la obra como una entidad abstracta que se puede manifestar en cualquier soporte o incluso aún sin que se haya manifestado a través de un soporte, como puede serlo una conferencia. Sin embargo, sí debe ser susceptible de ser divulgada o reproducida por algún medio, por lo que, como ya señalamos, la mera idea no es objeto de protección. Por lo anterior, la protección del derecho de autor al recaer sobre las obras, es independiente del soporte en el cual la obra se encuentra, por lo tanto la propiedad sobre el soporte material no implica la propiedad sobre la obra, pues esta seguirá siendo de su autor.

La jurisprudencia andina ha reiterado estos conceptos en varias interpretaciones prejudiciales, haciendo particular énfasis en la originalidad, entendiendo esta como requisito de existencia de la obra, no como sinónimo de novedad sino de individualidad, es decir, reitera el Tribunal Andino citando a Lipszyc, que para que la obra sea original se requiere que esta "exprese lo propio de su autor, que lleve la impronta de su personalidad" y continúa el Tribunal: "cuestión que debe examinarse en cada caso" (Tribunal 
de Justicia de la Comunidad Andina, 1999). El uso de estos criterios se realiza en el ámbito de las competencias de cada operador jurídico, por ejemplo, una oficina de registro de derecho de autor carece de competencia para otorgar o reconocer derechos sobre una determinada obra, pues dado que la protección es automática y el registro de derecho de autor meramente declarativo, este no puede ser denegado bajo alegaciones de falta de originalidad, pues ello significaría exceder sus funciones. ${ }^{5}$ La decisión sobre la originalidad de una obra se debe llevar a cabo por otro operador jurídico, el juez, quien, bajo la aplicación de los criterios antes señalados y caso a caso, determinará la existencia de tal requisito o no en caso de controversia. Por otro lado, un particular podrá realizar un examen preliminar sobre este aspecto, bien sea directamente o con apoyo jurídico a efectos de tomar la decisión si respecto de cierto objeto puede reclamar derecho de autor o no. Finalmente es el juez quien está llamado a tomar una decisión de fondo sobre la aplicabilidad del derecho de autor en el examen que hace de los objetos que se le presentan. Volviendo al ejemplo de la botella de vino, presentado en la introducción de este artículo, cuando un segundo productor de vino pretende usar una botella con la misma forma para comercializar su vino, si se alega protección por derecho de autor, es el juez quien deberá apreciar el objeto en concreto y con la ayuda de los criterios de protección y el soporte de peritos, deberá determinar si tales criterios se cumplen. Es él quien, en aplicación de los principios anteriormente señalados, deberá decidir si de hecho existe o no una obra y por lo tanto se puede decir de la misma que está protegida por el derecho de autor. Una decisión negativa en relación con la originalidad implicará que el segundo productor podría usar la botella para su producto, salvo, claro está, que adicionalmente esta haya sido registrada como diseño industrial.

5 El artículo 53 de la Decisión Andina 351 de 1993 (Comisión del Acuerdo de Cartagena, 1993) señala el carácter meramente declarativo del registro de derecho de autor en su artículo. Por su parte, el Tribunal Andino de Justicia ha señalado que si bien la originalidad es un requisito esencial para la protección de la obra, la misma se presume, y por lo tanto, quien la niega debe probarlo. De estas dos circunstancias se colige que no le es dado examinar la originalidad de la obra a la oficina de registro, pues ello la llevaría a tener que demostrar la falta de originalidad caso a caso, convirtiéndola en juez de tales casos, lo que excede sus funciones meramente declarativas (Tribunal de Justicia de la Comunidad Andina, 2010). 
Como ya se ha planteado, el principal criterio para la protección de las obras por el derecho de autor es el de la originalidad. Bajo este se establece que la obra debe expresar el aporte creativo del autor, aquello que la hace única y que revela el estilo de su creador. Tal originalidad no sale del ámbito subjetivo, donde se le otorga prevalencia a la figura del autor como determinante de la creación. En efecto, el Tribunal de Justicia de la Comunidad Andina ha reiterado este criterio en diferentes interpretaciones prejudiciales. $^{6}$

Otro criterio que soporta la protección otorgada por el derecho de autor, asociado a la originalidad, es el de la no protección de las ideas expresadas en la obra. Es decir que la obra es la expresión original de una idea, pero la idea en sí no es susceptible de protección. De allí que sea importante puntualizar con Ficsor (2003, pág. 292) que las ideas son comprendidas como los bloques básicos de la creación, pero no son la creación en sí. Para el mencionado autor, el concepto general de idea comprende además los procedimientos, los métodos o los conceptos matemáticos, que por lo tanto son excluidos de la protección del derecho de autor. Es por ello que el artículo 7 de la Decisión Andina 351 establece: "Queda protegida exclusivamente la forma mediante la cual las ideas del autor son descritas, explicadas, ilustradas o incorporadas a las obras. No son objeto de protección las ideas contenidas en las obras literarias y artísticas, o el contenido ideológico o técnico de las obras científicas, ni su aprovechamiento industrial o comercial."

Para precisar mejor lo anterior, vale la pena diferenciar el concepto de originalidad del derecho de autor del concepto de novedad utilizado en la propiedad industrial, con diferentes matices. La jurisprudencia andina ya mencionada ha señalado también la distinción entre el concepto de originalidad que se predica del derecho de autor, del concepto de novedad que se predica de la propiedad industrial, pues este último determina que, de existir un objeto similar a aquél respecto del cual se pretende protección, la existencia de dicho objeto previo afecta la posibilidad de protección del actual. En el mismo sentido, Ficsor (2003, p. 300) precisa esta distinción señalando que respecto la originalidad, la existencia de una creación similar

6 En efecto, los procesos 020-IP-2007 (Tribunal de Justicia de la Comunidad Andina, 2007) y 002-IP-2010 (Tribunal de Justicia de la Comunidad Andina, 2010) reiteran el criterio de originalidad en este sentido, como lo ha señalado la doctrina en múltiples ocasiones, por ejemplo, en el caso de Lipszyc (1993). 
a la obra no afecta la originalidad de la obra actual, especialmente en el caso en que el autor no haya podido tener acceso a la obra anterior.

Adicionalmente, por lo menos en el campo de la tradición continental del derecho de autor y en el marco del Convenio de Berna para la Protección de las Obras Literarias y Artísticas (Congreso de la República de Colombia , 1987), ${ }^{7}$ la protección otorgada a las obras es automática, lo que determina que basta la existencia de la obra para que se predique protección sobre la misma.

Por oposición, dentro de otra de las ramas de la propiedad intelectual, la propiedad industrial, las invenciones y los modelos de utilidad, así como los diseños y las marcas, responden a otros criterios de protección particulares, la novedad, la distintividad y en el caso de los diseños industriales un concepto complejo de novedad como será explicado más adelante. Adicionalmente, el nacimiento del derecho de propiedad industrial se encuentra supeditado a la concesión por parte del Estado por medio de un registro.

En cuanto a la diferenciación que se viene presentando, se debe examinar ahora el caso de los diseños industriales. El objeto de protección en este caso es la apariencia bidimensional o tridimensional externa del producto “...novedosa e intangible, formada por líneas, colores y textura (...) representa una creación susceptible de protegerse por un derecho de Propiedad Industrial (...)" (Astudillo Gómez, 2007, pp. 34, 35). El mismo autor señala que el sentido del diseño industrial es hacer más atractivo el producto al consumidor, no ya desde el punto de vista marcario, es decir, la distintividad del signo marcario, sino desde el punto de vista ornamental, que hace que el objeto se destaque entre sus competidores.

Sin embargo, llama la atención que se requiera de novedad en el diseño para que se pueda reclamar protección sobre el mismo. Es decir, que un diseño no debe ser original sino nuevo, o sea, que no existiera antes. De manera adicional a la novedad, el diseño no puede estar determinado por la utilidad o función del objeto al que se aplica.

7 En la actualidad son partes signatarias del Convenio de Berna 167 estados. (Organización Mundial de la Propiedad Intelectual, 2013). 


\section{El diseño, los derechos de propiedad industrial y la arbitrariedad}

En varias ocasiones, el derecho de autor y la propiedad industrial se traslapan en sus respectivos campos de protección. En algunos casos, las obras pueden ser objeto de protección de la propiedad industrial, como aquellas que siendo obras pueden cumplir la función identificativa o distintiva. En este artículo nos ocuparemos de la discusión relativa a la protección de las llamadas obras de arte aplicado a la industria y su alcance respecto de los diseños industriales como objeto de protección de la propiedad industrial.

¿Dónde deben ser ubicados los derechos de propiedad intelectual derivados del diseño? El diseño, los dibujos y modelos industriales suelen ser ubicados en los derechos industriales de naturaleza creativa, esto es, en el ámbito de las nuevas creaciones; sin embargo, los diseños, entendidos como nuevas creaciones, siguen parámetros diferentes de los tres requisitos esenciales de las invenciones (novedad, altura inventiva y aplicación industrial), pues, aunque requieren de novedad, esta es meramente formal a efectos de la concesión del derecho, ${ }^{8}$ y en cambio se busca que exista algún grado de libertad en las formas bidimensionales o tridimensionales del objeto que se configura como diseño industrial. Lo que cualifica al diseño industrial es la novedad en la apariencia externa de un producto, siempre que tal apariencia externa no esté determinada por la funcionalidad del producto mismo.

Ahora bien, los artículos 116, literal b) y 130 de la Decisión Andina 486 vinculan dicho grado de libertad con el concepto de arbitrariedad en las formas del diseño, en el sentido en que no será protegida aquella forma que dependa de consideraciones técnicas o de la función técnica al cual se aplica o "(...) que no incorpore ningún aporte arbitrario del diseñador." En efecto, el artículo 113 de la Decisión Andina 486 de 2000 señala que se trata de "la apariencia particular de un producto que resulte de cualquier reunión

8 Decisión Andina 486, Artículo 115.- Serán registrables diseños industriales que sean nuevos. Un diseño industrial no es nuevo si antes de la fecha de la solicitud o de la fecha de prioridad válidamente invocada, se hubiere hecho accesible al público, en cualquier lugar o momento, mediante su descripción, utilización, comercialización o por cualquier otro medio.

Un diseño industrial no es nuevo por el mero hecho que presente diferencias secundarias con respecto a realizaciones anteriores o porque se refiera a otra clase de productos distintos a dichas realizaciones. (Comisión del Acuerdo de Cartagena, 2000). 
de líneas o combinación de colores, o de cualquier forma externa bidimensional o tridimensional, línea, contorno, configuración, textura o material, sin que cambie el destino o finalidad de dicho producto" (Comisión del Acuerdo de Cartagena, 2000). Puede argüirse que la palabra cualquier daría a entender dicha arbitrariedad. El Tribunal Andino de Justicia ha aportado un elemento de análisis para la interpretación de esta norma desde su equivalente en la Decisión Andina 344 de 1994, artículo 58: se trata de la presencia de elementos ornamentales "(...) que otorgan al diseño su categoría" que hacen referencia a la finalidad estética del diseño en el sentido de otorgare una ventaja competitiva al producto no ya por su funcionalidad, sino por su apariencia (Tribunal de Justicia de la Comunidad Andina, 2013).9

El derecho europeo, a través de la Directiva 98/71/CE sobre la protección jurídica de los dibujos y modelos (Parlamento Europeo y Consejo, 1998), y en desarrollo de la misma el derecho español, han evolucionado en el criterio de protección de los diseños industriales y han incluido una prueba de dos pasos acumulativos en la que se solicita primero la novedad de éste y segundo, el carácter singular del mismo (Otero Lastres, 2005).

Esta singularidad es particular, pues hace referencia a la impresión de conjunto que pueda tener el examinador o el juez. Como lo resalta Otero Lastres (2005, pág. 211) respecto de la legislación española (artículo 7 de la Ley 20 de 2003) "El efecto o sensación que ha de producir en el ánimo la visión global del diseño es que tal diseño [difiera] de la impresión general que produzca cualquier otro diseño anterior." Un criterio para determinar dicha singularidad es el "(...) grado de libertad del autor a la hora de desarrollar el dibujo o modelo" Directiva 98/71/CE (Parlamento Europeo y Consejo, 1998). ¿Qué tan diferente es esto de la originalidad que el derecho de autor exige a la obra? Otero Lastres (Los requisitos de protección del diseño, 2005) entiende que en España, la Ley 20 de 2003 gradúa la creatividad en los diseños para que se entienda que tales creaciones cumplen con el requisito de singularidad y puedan ser protegidos por la propiedad industrial, y un mayor grado de creatividad para que tengan un carácter artístico y lleguen a la protección acumulada del derecho de autor como obra de arte aplicado. La originalidad es, en tal sentido, autónoma e intrínseca, pues atiende al aporte creativo del autor y no a la intención diferenciadora del diseño.

9 En el mismo sentido: (Tribunal de Justicia de la Comunidad Andina, 2013). 
Es importante reconocer que este requisito de singularidad se encuentra presente en la normatividad andina de manera diferente al ser un criterio auxiliar para determinar la novedad. Así, señala que "[u]n diseño industrial no es nuevo por el mero hecho que presente diferencias secundarias con respecto a realizaciones anteriores o porque se refiera a otra clase de productos distintos a dichas realizaciones" (inciso segundo del artículo 115, Decisión Andina 486, Comisión del Acuerdo de Cartagena, 2000).

De mayor importancia para los efectos de este trabajo resulta la reflexión del Tribunal Andino, en su interpretación prejudicial de 2013, cuando buscó precisar el concepto de elementos ornamentales. Al respecto dijo lo siguiente:

"si una creación de forma que cumple una función técnica, puede ser separada del efecto técnico producido, esta creación puede ser protegida por la figura del diseño industrial, mientras que si esta forma no pudiera ser separada, la protección adecuada sería por medio de la figura del modelo de utilidad" (Tribunal de Justicia de la Comunidad Andina, 2013).

Tal criterio de separabilidad de la función técnica de la función ornamental va a ser importante en el momento en que se deba examinar la aplicación de las normas de derecho de autor para la protección o no de los diseños industriales como obras de arte aplicado.

Argumentos similares ha presentado el mismo Tribunal en su decisión de 2010 (Tribunal de Justicia de la Comunidad Andina, 2010), en la que desarrolla la idea de la separabilidad entre la función estética u ornamental, y la función utilitaria del diseño. Dicha separabilidad no sería problemática de no ser porque el Tribunal, en la racionalización que esboza de estos criterios, desliza conceptos asociados al derecho de autor, particularmente derechos morales tales como el derecho de integridad: "(...) entre las facultades que comprende este derecho, figura la de poder exigir de cualquier explotante el respeto a la integridad del diseño original, tal y como su titular lo ha concebido $y$ realizado y desea que se mantenga; de modo que sin el expreso consentimiento del autor, no pueden introducirse por ningún concepto alteraciones, al difundir, publicar o reproducir su diseño", y de paternidad derivando un derecho de concepción "por lo que el cesionario del derecho deberá reconocer y exteriorizar, de ser el caso, de quién ha provenido la creación y, quién ha sido el cedente de 
los derechos en su favor". Ninguno de estos derechos es propio del derecho de propiedad industrial, ni está reconocido por el cuerpo normativo de la Decisión Andina 486 de 2000.

Puede evidenciarse entonces cómo desde la manera en que trata de establecerse el objeto de protección del diseño industrial se camina cercanamente en el límite del derecho de autor. De hecho, el Tribunal en su decisión del 2010 sigue esa vía, con base en un artículo de la Organización Mundial de la Propiedad Intelectual en el que se reafirma el criterio de separabilidad entre las funciones utilitarias y las funciones estéticas para el diseño industrial (Organización Mundial de la Propiedad Intelectual OMPI, 2002). El error consiste en confundir la ornamentación y la separabilidad de las funciones utilitarias como requisito de protección para el diseño industrial, con la estética que eventualmente podría predicarse de algunos diseños industriales. En efecto, el documento de la OMPI señala que la función utilitaria del objeto tiene un carácter económico protegido por el derecho de patentes o modelos de utilidad, y que el carácter ornamental del diseño es estético. Olvida dicho documento que el sentido de la protección del diseño industrial es fundamentalmente económico, pues se protege la apariencia externa del producto que lo hace llamativo al consumidor y por lo tanto diferente, aunque no diferente en su aspecto técnico funcional, de otros productos no ornamentados: "A diferencia de las características técnicas, las características no funcionales del aspecto exterior del producto, es decir, el diseño, no son un elemento indispensable desde el punto de vista económico para la competencia. (Organización Mundial de la Propiedad Intelectual OMPI, 2002 , p. 4). Si ello fuera así, no habría sentido en la protección por medio del diseño industrial de tal diferencia, pues su valor económico carecería de fundamento. La ventaja competitiva que el diseño industrial genera no es asociada a una funcionalidad técnica, que de hecho excluye expresamente, sino a la apariencia del producto que lo hace más deseable para el consumidor. Múltiples ejemplos se podrían recordar al efecto, pero para simplificar puede tomarse aquello que hace que una pluma-fuente cambie en su precio dependiendo de su diseño.

Precisando, la jurisprudencia andina es consistente en aplicar el criterio de ornamentación para entender la protección del diseño industrial, ornamentación que se separa de la función utilitaria del producto en sí. Como lo señala la OMPI “... los diseños industriales están a caballo entre las artes y la 
tecnología pues los diseñadores industriales se esfuerzan por crear productos cuya forma o aspecto exterior satisfagan la preferencia estética de los consumidores y respondan a las expectativas de estos últimos en cuanto al funcionamiento de los productos" (Organización Mundial de la Propiedad Intelectual OMPI, 2002 , p. 3). Pero es inconsistente al tratar de aplicar a todos los diseños prerrogativas del derecho de autor. Con la anterior cita se demuestra la contradicción del documento OMPI antes citado, pues en muchos casos la apariencia externa del producto no está determinada por la autonomía del diseñador, sino por las preferencias estéticas del consumidor, preferencias que suelen ser resultado de extensos estudios de mercado donde el resultado es lejano del aporte del creativo, pero si competitivamente llamativo. La mera ornamentación no significa que se pueda predicar de todo diseño una obra y por lo tanto derechos morales sobre aquellos.

Adicionalmente, la problemática que surge de estas condiciones por las que se reconocería una especie de "derecho moral de autor" al diseñador por su diseño industrial parte del hecho de que en materia de derecho de autor el registro no es requisito de la protección, pero en los diseños sí. Por lo tanto, tales derechos sólo surgirían a la vida jurídica solamente si se otorga el registro del diseño. Esto sería contradictorio, pues el derecho moral no podría estar sujeto a reconocimiento vía registro dada su naturaleza, pues uno de los derechos morales protegidos es precisamente el de no dar a conocer la obra si no se quiere.

\section{La problemática relacionada con las obras de arte aplicado y los diseños industriales}

La presencia de la arbitrariedad ha dado lugar a que exista a su vez la posibilidad de que esa forma ornamental incorporada al producto para hacerlo más atractivo al consumidor pueda cumplir eventualmente los requisitos generales para que la misma sea comprendida como una obra y por lo tanto pueda ser protegida también por el derecho de autor. Esta es una de las formas en que se produce un contacto entre dos de las disciplinas que aborda la propiedad intelectual, el derecho de autor y la propiedad industrial. Se trata de la conexión producida por las denominadas obras de arte aplicado a la industria, específicamente a los diseños industriales. 
¿En qué casos se puede aplicar el derecho de autor respecto de un diseño industrial?, ¿en qué casos el diseño industrial no puede ser una obra?, ¿qué implicaciones tiene que un diseño industrial sea a su vez protegido como una obra por el derecho de autor?

Estas inquietudes se han tratado de resolver en diferentes legislaciones de distintas maneras. Se trata de los sistemas de acumulación o no del derecho autor respecto de la propiedad industrial.

Existen otros puntos de contacto entre estas dos disciplinas, como es el caso del uso de obras artísticas para marcas, o la existencia de obras literarias dentro de las solicitudes de patente, o la aplicación de software en invenciones. Pero este escrito no se ocupará de tales posibilidades, enfocándose únicamente en el tema de las obras de arte aplicado.

\section{Los artículos 4. j), 3. l) y n), y 1. de la Decisión Andina 351 de 1993}

De conformidad con la Decisión Andina 351 de 1993, artículo 52 “ $\mathrm{La}$ protección que se otorga a las obras literarias y artísticas, interpretaciones y demás producciones salvaguardadas por el derecho de autor y los derechos conexos, en los términos de la presente Decisión, no estará subordinada a ningún tipo de formalidad. En consecuencia, la omisión del registro no impide el goce o el ejercicio de los derechos reconocidos en la presente Decisión" (Comisión del Acuerdo de Cartagena, 1993).

Por lo tanto, y también de acuerdo con el principio establecido por el artículo 5.2 del Convenio de Berna, la protección otorgada por el derecho de autor a las obras no depende de formalidad alguna.

El artículo 4 de la Decisión Andina 351 de 1993 hace referencia al campo de aplicación del derecho de autor, según el cual la protección de esta disciplina recae sobre todas las obras literarias, artísticas y científicas, y condiciona que tales obras puedan ser susceptibles de reproducción o divulgación por cualquier medio o procedimiento. El literal j) de la mencionada norma establece a su vez la protección de las obras de arte aplicado como tipo especial de obra, separado de las obras de bellas artes del literal g). Siguiendo a Ficsor (2003, p. 33), esta es una de las posibilidades que el Convenio de Berna otorga a los países miembros en relación con la protección de este tipo de creaciones. Cada país podrá decidir el campo y las condiciones de protección de estas, de conformidad con el artículo 2.7 
del mencionado instrumento internacional (Congreso de la República de Colombia, 1987). ${ }^{10} \mathrm{El}$ análisis necesario para determinar cuándo se está ante una obra de arte aplicado no puede ser subjetivo y tiene que fundamentarse en criterios legales y jurídicos. Respecto de la obra en general, el derecho de autor cuenta con los criterios de protección ya señalados anteriormente. ${ }^{11}$

Ahora bien, para determinar que se trata de una obra de arte aplicado, es necesario entender que los términos de arte e industria difieren ostensiblemente en la definición que utiliza la Decisión Andina 351 de 1993, artículo 3, n) la cual señala que las obras de arte aplicado son creaciones artísticas con funciones utilitarias o incorporadas en un artículo útil, ya sea una obra de artesanía o producida a escala industrial. Valga aclarar que la producción a escala artesanal o industrial es apenas un elemento contingente en la definición de la obra de arte aplicado.

En tal definición lo primero a determinar es si se está ante una obra, de acuerdo con la definición que de la misma da la Decisión Andina 351 de 1993, artículo 3, es decir que se trate de una "creación intelectual original de naturaleza artística, científica o literaria, susceptible de ser divulgada o reproducida en cualquier forma". Así pues, la obra debe ser fruto de la creación original de un autor, expresada en el campo literario o artístico; no se considera como obra una idea, o un método, pues estos no son objeto de protección por el derecho de autor, como ya ha sido aclarado.

Lo segundo a determinar es si se trata de una obra de arte, una creación artística. Así, y de nuevo volviendo a la definición legal que de la obra de arte aplicado da la misma Decisión Andina 351, no se trata de cualquier obra, se trata de una "creación artística con funciones utilitarias o aplicada a un artículo útil", es decir que la obra tiene una calidad especial, que debe ser artística.

Así pues, no puede confundirse el arte con la obra, pues el arte, en sentido general como idea, no es objeto de protección por el derecho de autor.

10 Dice así el mencionado artículo del Convenio de Berna: "Queda reservada a las legislaciones de los países de la Unión la facultad de regular lo concerniente a las obras de artes aplicadas y a los dibujos y modelos industriales, así como lo relativo a los requisitos de protección de estas obras, dibujos y modelos, teniendo en cuenta las disposiciones del Artículo 7.4) del presente Convenio. Para las obras protegidas únicamente como dibujos y modelos en el país de origen no se puede reclamar en otro país de la Unión más que la protección especial concedida en este país a los dibujos y modelos; sin embargo, si tal protección especial no se concede en este país, las obras serán protegidas como obras artísticas."

$11 \mathrm{Al}$ efecto, consultar Lipszyc, D., (1993). Derecho de autory derechos conexos (1 ed.). Buenos Aires: Zavali- Unesco-Cerlalc. 
Aquello protegido es el resultado de la actividad del arte, como disciplina, que dé lugar a una obra creada por una persona, cumpliendo en términos del derecho de autor con las condiciones de protección de originalidad, no protección de las ideas, etc.

De lo anterior se deduce que existen muchas manifestaciones que son artísticas por su naturaleza, pero que no son obras en su esencia, como de hecho el derecho mismo lo reconoce al hacer una profunda diferenciación entre dos actividades artísticas, la creación de obras musicales, la cual por su naturaleza implica la protección del derecho de autor respecto de tal creación, y por otra parte, la interpretación o ejecución de las obras musicales por un artista, intérprete o ejecutante, para la cual reconoce derechos conexos al derecho de autor. No hay duda de que ambas actividades son de naturaleza artística, pero mientras la primera es objeto de protección por el derecho de autor, la segunda no lo es. Precisamente porque allí no hay creación, aunque si una actividad artística que recibe una protección distinta que se ha denominado en nuestra legislación como el derecho conexo del artista, intérprete o ejecutante.

$\mathrm{Al}$ analizar la definición expuesta por el Diccionario de la Real Academia de la Lengua Española, la palabra arte tiene más de una acepción (se citan las cinco primeras):

Arte:

1. amb. Virtud, disposición y habilidad para hacer algo.

2. amb. Manifestación de la actividad humana mediante la cual se expresa una visión personal y desinteresada que interpreta lo real o imaginado con recursos plásticos, lingüísticos o sonoros.

3. amb. Conjunto de preceptos y reglas necesarios para hacer bien algo.

4. amb. Maña, astucia.

5. amb. Disposición personal de alguien. Buen, mal arte (Real Academia Española, 2013).

Ahora, el mismo diccionario define lo artístico como lo "perteneciente $o$ relativo a las artes, especialmente a las que se denominan bellas." De allí que una creación artística pertenece a las artes. En cuanto a este punto, es necesario hacer una diferenciación clara, ya que el derecho de autor protege las obras en general, y dentro de ellas, las obras de arte, y particularmente las obras 
de arte aplicado. En dicho orden de ideas, si bien es cierto que la obra en sentido general puede no ser artística, ello sí debe predicarse de la obra de arte aplicado, es decir que finalmente la obra de arte aplicado, primero debe ser una obra artística y segundo tal obra de arte debe ser aplicada, incorporada o ser en sí misma un artículo útil. Al efecto, el mismo artículo 3 de la Decisión Andina 351 de 1993 define la obra de arte como aquella que apela al sentido estético de quien la contempla.

Ficsor (2003, pág. 267) al tratar de definir la obra artística, le hace un flaco favor al derecho de autor, pues en lugar de definirla, la generaliza señalando que la obra de arte en términos generales es aquella que no es una obra literaria. Tal explicación parece huir del debate que se reclama y por lo tanto todo puede ser artístico. La razón para ello es revelada por Otero Lastres (2005), quien al explicar el sistema de acumulación plena del derecho de francés - donde no se diferencia la obra de arte del diseño industrial-, se introduce un elemento que nuestra legislación comunitaria y nuestra legislación nacional acogen, pero que no es establecido en la normatividad internacional. Tal es el criterio según el cual el derecho de autor protege las obras sin importar el mérito o el valor artístico de las mismas. El autor ibérico hace caer en cuenta de que esta condición no se encuentra en la legislación española, como si se encuentra en la francesa, y que por tal razón, mientras la segunda adopta la acumulación plena, España cuenta con un sistema de acumulación gradual o restringida.

El razonamiento de Otero Lastres es pertinente pero incompleto; deja que la presencia o ausencia de un concepto que ha evolucionado en el derecho de autor, el relacionado con la no atención al mérito o valor artístico de la obra, como garantía de la libertad de expresión (Álvarez Amézquita, 2007), sea el determinante para resolver la acumulación de los sistemas de protección en el caso de los diseños. Sin embargo, aquí se sostiene que el carácter artístico es diferente al mérito artístico. Claramente, el derecho de autor no podría ingresar al terreno de la estética y definir que sólo lo bello es protegido por el derecho de autor, pues ello iría directamente en contra de la libertad de expresión y la creatividad.

Entonces, ¿cómo definir si se está ante una obra de arte, jurídicamente hablando? La definición de arte otorgada por la ley es apenas un criterio auxiliar, pues si se le pregunta a la estética qué es lo bello o qué es el arte, podrá haber tantas respuestas como personas a las que se les pregunte. 
La obra de arte u obra artística, en el ámbito jurídico, es la que apela al sentido estético de quien la contempla. Tal es el sentido que le encuentra el Glosario de la OMPI sobre Derecho de Autor y Derechos Conexos: “(...) es una creación cuya finalidad es apelar al sentido estético de la persona que la contempla. (...) Análogamente, la mayoría de las legislaciones incluyen en esta categoría las obras de arte aplicado" (Boytha, 1980, p. 13). Ahora bien, la definición antes citada no habla de la calidad belleza en la obra de arte, simplemente señala que su forma de expresión como obra apela al sentido estético de las personas, es decir que queda en manos del espectador de la obra, el atribuirle la belleza o no a la misma.

Pero ante todo la obra debe ser de carácter artístico, lo cual no puede confundirse en ningún caso con una valoración de su mérito, calidad o destino. Si un determinado objeto, respecto del cual se reclama su carácter de obra de arte aplicado, no es una obra de carácter artístico, no tiene sentido examinar su aplicación a la industria, pues para efectos de los criterios de protección del derecho de autor esto sería irrelevante. Se trataría, por ejemplo, de materiales u objetos que carecen de carácter artístico y que en dado caso sus formas o colores se destacan con el fin de diferenciarse en un mercado. En éste último caso, el campo de su protección sería únicamente el del diseño industrial y no podría acumularse el otorgado por el derecho de autor. No habría lugar a acumulación, pues una de las características principales para que el derecho de autor surja a la vida jurídica no existiría. Antequera Parilli, señala:

"Pero la posible acumulación no quiere decir, en nuestro criterio, que sea 'automática', sino que para reclamar la protección como obra de arte aplicado, el diseño debe reunir las condiciones existenciales de una obra, vale decir, que se ubique en el dominio artístico, y que por su forma de expresión, tenga características de originalidad (...)" (Antequera Parilli, 1997, p. 371).

Lo anterior no puede confundirse con la existencia de casos en los cuales la protección que brinda el derecho de autor, sobre las obras artísticas, coincida con la protección que otras disciplinas brindan. Es allí donde tiene aplicación lo señalado por el tratadista Antequera Parilli al mostrar puntos de contacto en los que coincide el derecho de autor y la protección que brinda la propiedad industrial. 


\section{Diferentes teorías sobre la acumulación de la protección entre el derecho de autor y la protección a los diseños industriales}

Ante la pregunta de si existen casos en los que un objeto puede ser a su vez protegido por el derecho de autor y por la propiedad industrial, como es el caso de las artes aplicadas y la protección de los modelos o dibujos industriales, ya se ha señalado que pueden encontrarse tres sistemas o posibles soluciones adoptadas por el derecho comparado para resolver la vinculación entre las dos disciplinas (Gaubiac, 1982).

\section{Separabilidad}

La primera de las soluciones es el denominado como criterio de disociación del producto, o criterio de separabilidad, el cual, como fue señalado más arriba, fue establecido en nuestra legislación a través del entonces vigente artículo 6 de la Ley 23 de 1982 (Congreso de la República de Colombia, 1982).

Según esta norma, la protección que brindaba el derecho de autor sobre una obra de arte aplicado dependía de que el valor artístico de la obra pudiera ser separado del carácter industrial del objeto u objetos en las que éstas eran aplicadas.

Tal criterio separa la obra como creación del objeto al cual se aplica o incorpora y reclama para la protección del derecho de autor que la obra tenga un valor artístico disociable del carácter industrial al cual aquella se aplica. $^{12}$

En materia de derecho de autor, el criterio de separabilidad se entiende suspendido por la definición que de la obra de arte aplicado hace la Decisión Andina 351 de 1993, artículo 3, pues la misma no hace ninguna distinción, sino que establece que la obra de arte aplicado es una "creación artística con funciones utilitarias o aplicada a un artículo útil".

12 Cabe recordar que en relación con el diseño industrial, el Tribunal Andino ha reclamado condiciones similares a este criterio para la protección del mismo. Para el caso de los diseños industriales se ha señalado que si la creación cumple una función técnica que puede ser separada del efecto técnico, esta sería un diseño industrial, de lo contrario sería un modelo de utilidad (Tribunal de Justicia de la Comunidad Andina, 2013). 


\section{Acumulación plena}

Otra de las soluciones que se han dado en las legislaciones es la acumulación plena o absoluta (Otero Lastres, 2005), desarrollada principalmente por la legislación francesa, (teoría de la unidad del arte) en la que el criterio de protección de un diseño industrial como obra protegida por el derecho de autor solo hace alusión a que el referido diseño cumpla con los requisitos propios del derecho de autor, aun cuando su naturaleza sea industrial. En efecto, así lo señala Otero Lastres al examinar la evolución del derecho francés respecto de este tema. Dice el mencionado autor:

De lo hasta aquí expuesto en cuanto al derecho francés, resulta: 1) que inicialmente la Ley de 1793 solamente protegía las obras de arte puro; 2) que la Ley de 1806 se aplicaba exclusivamente a los dibujos y modelos; 3) que el alcance inicial de la modificación introducida por la Ley de 1902 en la Ley de 1793, consistente en la expresión «cualquiera que sea el mérito o destino de la obra", fue extender la aplicación de esta Ley de 1793 a las obras del arte industrial, pero siempre, claro está, que fuesen obras de arte; 4) que la Ley de 1909 acogió a nivel legislativo la teoría de la unidad del arte y el sistema de acumulación absoluta, lo cual implicaba que todo dibujo o modelo era protegible por la propiedad intelectual; $5^{\circ}$ ) que la Ley de 1957 confirmó la teoría de la unidad del arte; y 6²) que el Código de la Propiedad Intelectual no se limita a disponer en sede de dibujos y modelos que estos pueden beneficiarse de la protección de la propiedad intelectual [derecho de autor], sino que, además, contiene una remisión expresa en el artículo L513-2 a las normas de su Libro I, relativas al derecho de autor, lo cual permite incluir el dibujo o modelo entre las obras protegibles (Otero Lastres, 2005, pp. 96, 97) (subrayado por el autor). ${ }^{13}$

Es importante señalar que la teoría de la unidad del arte determina como una de sus primeras condiciones para que el diseño sea comprendido como una obra de arte aplicada, que el mismo sea una obra de arte primero. Sin embargo, reconoce de manera expresa la protección de las

13 Una aclaración aparece importante aquí, pues el derecho español denomina propiedad intelectual al derecho de autor, lo que genera algunas veces posibles confusiones entre la especie y el género al ser llamados de la misma manera. 
creaciones de las industrias de temporada de la confección y la fabricación de joyas y aderezos personales.

\section{Acumulación restringida}

La tercera solución es la señalada por Otero Lastres (2005) como el sistema de acumulación restringida, o de cúmulo parcial (Gaubiac, 1982), donde la acumulación de las protecciones del derecho de autor y de los diseños y modelos industriales se da solamente para "(...) ciertos tipos de obras "los modelos artísticos" $u$ "obras de arte aplicado a la industria» pueden beneficiarse de la doble protección" (Otero Lastres, 2005, p. 98). Las obras artísticas requieren, de acuerdo con este principio, un hecho generador que es la creación misma, sin la cual no habría obra, sino, simplemente, un diseño sobre el cual no se podría acumular la protección del derecho de autor.

En conclusión, Otero Lastres señala que la principal diferencia entre la teoría de la unidad del arte, es decir de la acumulación plena del derecho francés, y la acumulación restringida que se enmarca en el derecho español, consiste en que para el caso de la legislación francesa, la protección del derecho de autor no atiende al mérito o valor artístico de la obra ni a su destino, y que de manera expresa reconoce la protección de las creaciones de las industrias de temporada, mientras que para la legislación española, como sucede con la legislación comunitaria andina, la protección de las obras "exige a las obras artísticas un grado determinado de creatividad y de originalidad, que no poseen dichos diseños". Así lo ha reiterado la OMPI citando a Otero Lastres (Organización Mundial de la Propiedad Intelectual OMPI, 2002, p. 113).

\section{Discusión}

Se considera que la normativa andina, al señalar que la obra de arte aplicado es una creación artística con función utilitaria o aplicada a un artículo útil, acoge el criterio de la acumulación restringida, reclamando, como ya se ha señalado, primero originalidad, como se predica de cualquier obra protegible por el derecho de autor, y dos, carácter artístico (que no valor artístico), y esto determina el alcance del examen que debe hacer un 
operador jurídico respecto de lo que se pretende proteger estableciendo si el objeto es meramente un diseño o si consiste en una obra de arte que puede ser un diseño.

Aun si se entendiera que la legislación comunitaria andina recoge la teoría de la unidad del arte de la legislación francesa, es importante entender que, como lo ha señalado Gaubiac al presentar dicha teoría, "la presencia $o$ falta de carácter artístico seguirá siendo siempre el epicentro de los debates sobre los dibujos y modelos" (1982, p. 62).

El mismo autor señala cómo al interior de la teoría de la unidad del arte, la falta de carácter artístico de algunos objetos ha sido un elemento importante en la consideración de los tribunales, según los cuales se limita "(...) la protección del derecho de los dibujos y modelos fundándose en la falta de esfuerzo de creación de finalidad estética y de carácter artístico" (Gaubiac, 1982).

En consecuencia de todo lo anterior, no cabría argumentar que cualquier material resultado de una combinación de formas y/o colores arbitraria destinada a producir un efecto diferenciador de un producto en el mercado sea per se una obra de arte aplicado. Se requiere un primer análisis de si aquello es una obra de arte, es decir, si apela al sentido estético de quien la contempla.

El siguiente problema será determinar si el objeto satisface tal característica. La falta de criterios para valorarlo genera la necesidad de operar en sentido inverso, es decir, entrar a definir aquello que no es una obra de arte. Por ejemplo, encontrar si la forma del objeto en cuestión carece de originalidad, como puede ser la forma redonda de un balón, o en el caso que se ha usado como ejemplo en este artículo, una botella de vino común, cuyo color está determinado por la función de protección del contenido de la botella, al igual que su forma. Es decir, establecer aquellos casos en los que sus formas y apariencia solo obedecen a criterios técnicos y utilitarios, o son necesarios dada su naturaleza. La explicación lógica sería, simplemente, si el objeto no cumple con los requisitos mínimos de protección para ser un diseño industrial, mucho menos sería una obra de arte aplicado.

Aquí quizá sea de utilidad la presentación de ejemplos gráficos. Vale la pena diferenciar las famosas botellas creadas por Salvador Dalí (2014) ${ }^{14}$ de otras botellas simples, como cualquier botella de vino o de cerveza, cuya

14 El sitio web del autor ofrece múltiples ejemplos de ello. 
forma y color están determinados para la preservación del contenido. La forma de las primeras va más allá de la forma necesaria, pero también va más allá de la simple arbitrariedad, las botellas de Dalí, en cambio, buscan transmitir algo, es decir apelar al sentido estético de quien las contempla, no simplemente diferenciarse.

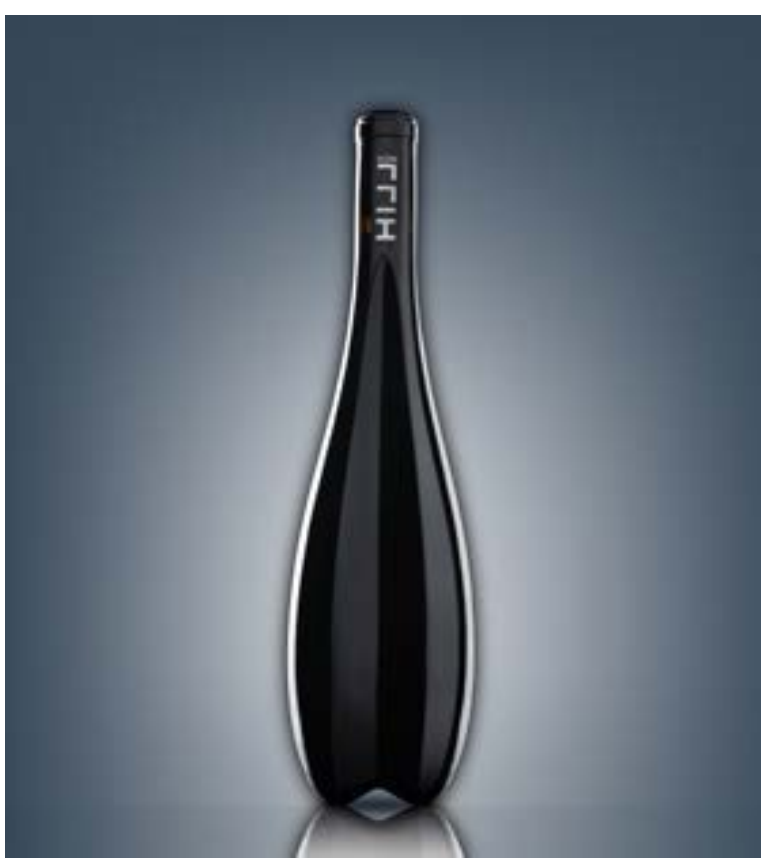

Ilustración 2. Icon Hill

Fuente: (Hadid, 2013).

Por otra parte, el análisis de las formas de las botellas da lugar a la reflexión respecto de la manifiesta necesidad de las mismas (ilustración 1 , vista más arriba), la boca de las botellas, por ejemplo, necesaria en su forma para que la tapa pueda ser utilizada, como la forma de la base, o el cuello, son formas que carecen de un carácter artístico. Así mismo, ocurre con el resto de las formas generales de estos objetos en los que al hacer un análisis de conjunto se evidencia una similitud relevante entre muchas. Todas estas botellas, si bien son diferentes, no tienen el carácter artístico, dado que su diferencia se basa en el sentido de generar una determinada identidad con el producto que envasan, ninguna de tales formas apela al 
sentido estético de quien las contempla, como se ha señalado respecto de la definición de una obra de carácter artístico. Cosa diferente sucede con los casos de la ilustración 2, donde es necesario entrar a aplicar los criterios aquí expuestos. En tal caso, podría decirse que si sus formas fueran únicamente funcionales, estarían alejadas del derecho de autor, pero esto no puede decirse de la ilustración 2 .

Otro elemento de análisis puede ser el uso de objetos no artísticos como obras de arte. En algunos casos se ha tendido a confundir el sentido del camino que se sigue al respecto. De nuevo, quizá un ejemplo sirva para evidenciar el caso. La famosa "Fuente" creada por Marcel Duchamp (1917)15 (ilustración 3), establece sin problemas su carácter de obra artística pese a ser en sí misma un objeto o artículo útil. No por ello se puede decir que es una obra de arte aplicado, porque tal razonamiento solo funcionaría en la vía por la cual el autor crea una obra de arte con funciones útiles, pero no todo objeto común es una obra de arte en sí mismo.

Veamos, Duchamp toma un orinal y lo emplaza en un salón de arte, le pone una firma y lo titula "Fuente". Más allá de la propia reflexión que el autor haya querido generar en relación con el arte mismo, el orinal en sí no es más que un objeto con funciones claramente utilitarias, convertido en una obra de arte. ¿Será entonces que todos los orinales son ahora obras de arte? Seguramente no. ¿Quién está llamado a definir si algo es o no una obra de arte? La respuesta, en principio, es más simple de lo que se puede pensar, es el autor quien lo puede hacer, describiendo su proceso creativo. Si por ejemplo el proceso creativo implica el uso de una determinada forma, porque las condiciones del mercado y los estudios de mercadotecnia señalaron que esa determinada forma o color sería preferida por los consumidores, entonces no habría ni originalidad ni carácter artístico en tal creación. ¿Puede el autor mentir e inventarse una explicación artística a una creación que no lo es? Probablemente sí, pero es allí donde los peritos y los criterios del juez afloran para decidir en el caso concreto, pues el principio de buena fe cobijaría a dicho autor.

En este punto se puede señalar un argumento adicional. Darle tal preponderancia al autor es congruente con el sistema de derecho de autor respecto del cual se busca protección.

15 Una imagen de esta obra puede ser vista en el sitio web de la Tate Modern Art Gallery. 


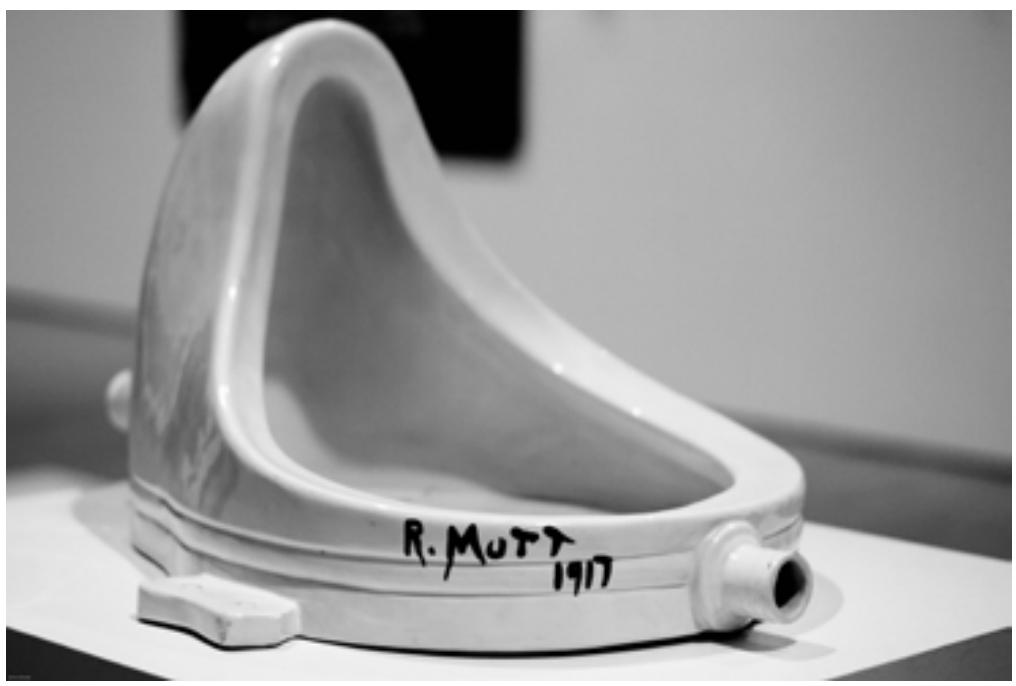

Ilustración 3. Fountain

Fuente: (Duchamp, 1917).

Lo importante de esta problemática radica en el efecto que la acumulación de protecciones jurídicas puede generar. Como es evidente, el derecho de autor es sumamente atractivo para la industria, ya que su protección es automática, global en los términos del principio de trato nacional establecidos por el Convenio de Berna, comprende derechos morales y patrimoniales, y, adicionalmente, goza de extensos plazos de protección. En el caso colombiano y en el caso andino, dado que la Decisión Andina no hace distinción alguna en el tratamiento que otorga respecto del plazo de protección otorgado a las obras de arte aplicado, estas se entienden protegidas por el mínimo comunitario, es decir cincuenta años después de la muerte del autor, o de acuerdo con la legislación de cada país andino, lo que en el caso de Colombia significa una protección por vida del autor más ochenta años después de su muerte.

Llegar al extremo de proteger por vía de derecho de autor objetos destinados a promover la competitividad comercial de un determinado producto es sumamente arriesgado, pues el reducido margen de protección otorgado para tales creaciones se amplía en detrimento de los competidores. Tal competitividad se desarrolla en términos comerciales y económicos, más no necesariamente creativos. Es allí donde dibujar la línea es importante, 
pues por una parte el riesgo de una plena acumulación generaría una extensión de las prerrogativas de un derecho en un campo que le es ajeno, pero la acumulación parcial es necesaria, dado que las artes aplicadas son ciertamente un campo en el que pueden coexistir el derecho de autor y el derecho de propiedad industrial relativo a los diseños industriales.

Lo señalado por Otero Lastres (2005) en relación con la no atención al mérito artístico como criterio para la protección del derecho de autor no colisiona con la reclamación de carácter artístico evidentemente mencionado en la normativa andina. Se difiere así de lo expresado por otros autores, quienes consideran que la acumulación plena es la única salida en el sistema comunitario andino. Así, por ejemplo, Vega Barón (s.f.) considera que el diseño industrial se hace atractivo desde el punto de vista estético en general, opinión con la que se difiere, como ya se expresó, respecto del criterio de arbitrariedad y la función diferenciadora en el mercado, la cual es fundamentalmente la que razona su protección. La autora anteriormente mencionada se apoya en el principio según el cual el derecho de autor no atiende al mérito o al destino de la obra para otorgar su protección. Sin embargo, se debe resaltar que el camino por el cual el destino de una obra de arte no impida su protección por derecho de autor no implica per se que de vuelta opere de manera idéntica, es decir que todo diseño industrial sea una obra protegida por el derecho de autor. No se trata aquí de la escisión entre arte y técnica, camino ya superado por la legislación andina, sino de una racionalización de la acumulación de sistemas jurídicos. Agrede a la lógica que la acumulación sea plena, pues ello implicaría que uno de los dos sistemas es fútil respecto del otro.

\section{Conclusión}

El caso de los diseños industriales y su protección como obras de arte aplicada ha generado amplios debates. Los tres sistemas reconocidos por la doctrina internacional para resolver esta problemática ofrecen salidas dispares. Tan contrario al derecho de autor es aplicar el criterio de separabilidad del derecho italiano, actualmente suspendido por la legislación andina en Colombia, como aplicar el criterio de acumulación plena del derecho francés extendiendo el derecho de autor a campos del comercio donde la 
ventaja competitiva otorgada por la propiedad industrial resultaría irrisoria en comparación con la otorgada por el derecho de autor.

La dificultad en aplicar el criterio de acumulación parcial, dada su cercanía al criterio de no atención al mérito o al valor artístico en la evaluación de la obra como objeto de protección por el derecho de autor, hace que este no siempre sea bien recibido por la doctrina y aún menos por los operadores jurídicos, pues pone en su campo de acción una discusión que no es fácil de asumir. Por ello es relevante resaltar que aplicar la acumulación parcial requiere de ciertos criterios:

Que se trate de una obra en términos de derecho de autor. Es decir, que cumpla con los requisitos de originalidad y no protección de las ideas. Aquella forma que es determinada por los criterios técnicos de un determinado producto, por el color verde de una botella de vino que es necesario para la conservación del licor, no puede ser considerado como original, ya que ni siquiera es considerado como arbitrario en el sentido del diseño industrial.

El carácter artístico de la obra, lo que no es igual al mérito artístico. Este último es imposible de valorar de manera objetiva, pero el primero sí puede serlo por medio de exclusión respecto de lo que no se consideraría artístico, es decir, aquello que no apela al sentido estético de quien lo contempla. Además, como ya fue señalado, si un determinado objeto, respecto del cual se reclama su carácter de obra de arte aplicado, no es una obra de carácter artístico, no tiene sentido examinar su aplicación a la industria.

Que el autor mismo sea capaz de buena fe de señalar su proceso artístico. Una valoración caso a caso es necesaria por parte del operador jurídico, la aplicación de los criterios rectores del derecho de autor y de la propiedad industrial en sus respectivos campos, debe realizarse con el cuidado necesario para no usar herramientas de uno en otro.

Finalmente, defender el carácter artístico de una obra depende mucho de quien la creó y de cómo fue creada, así como de la obra misma. El juez en ello debe apoyarse en peritos técnicos, pero también en el sentido común. 
Por lo anterior se considera que el criterio de acumulación parcial es acorde con la legislación colombiana aplicable, así como congruente con los criterios de protección de los sistemas jurídicos en contacto. La aplicación de la acumulación plena es más simple, pero pone en riesgo la naturaleza misma del derecho de autor al extender su campo de protección a elementos creados con fines de ventaja comercial.

\section{Referencias}

Álvarez Amézquita, D. F. (2007). La libertad de expresión como resultado y garantía principal del derecho de autor. Revista Iberoamericana de Derecho de Autor, 1(1).

Álvarez Amézquita, D. F. (2011). Elementos para la consideración de la propiedad intelectual en una política de diseño. Acto, 11(1), pp. 34-41.

Antequera Parilli, R. (1997). La protección de las artes aplicadas y los diseños industriales (¿Propiedad Industrial o Derecho de Autor?). En OMPI, Ministerio de Educación y Cultura, E IIDA, 110 años de protección internacional del derecho de autor: Berna 1886-Ginebra 1996 : 3er Congreso Iberoamericano sobre Derecho de Autor y Derechos Conexos (págs. 363-376). Madrid: Organización Mundial de la Propiedad Intelectual: Ministerio de Educación y Cultura : Instituto Interamericano de Derecho de Autor.

Astudillo Gómez, F. (01-12 de 2007). Aproximación al Estudio del Diseño Industrial, Homenaje Póstumo al Doctor Miguel Arteaga Bracho. Propiedad Intelectual, $V I(10)$, pp. 21-62.

Boytha, G. (1980). OMPI Glosario de derecho de autor y derechos conexos. Ginebra: Organización Mundial de la Propiedad Intelectual - OMPI.

Comisión del Acuerdo de Cartagena. (17 de Diciembre de 1993). Decisión Andina 351. Régimen Común sobre Derecho de Autor y Derechos Conexos. Gaceta Oficial del Acuerdo de Cartagena.

Comisión del Acuerdo de Cartagena. (2000). Decisión Andina 486, Régimen Común sobre Propiedad Industrial. Gaceta Oficial de la Comunidad Andina.

Congreso de la República de Colombia. (26 de octubre de 1987). Ley №33. Por medio de la cual se aprueba el "Convenio de Berna para la Protección de las Obras Literarias y Artísticas", del 9 de septiembre de 1886, completado en París el 4 de mayo de 1896, revisado en Berlín el 13 de noviembre de 1908, completado en. Diario Oficial. Bogotá, Colombia. 
Congreso de la República de Colombia. (21 de Diciembre de 1979). Ley 46 de 1979. Por medio de la cual se autoriza al Gobierno Nacional para suscribir la adhesión de Colombia "al Convenio que establece la Organización Mundial de la Propiedad Intelectual", firmado en Estocolmo el 14 de julio de 1976. Diario Oficial(35417). Bogotá, Colombia.

Congreso de la República de Colombia. (28 de Enero de 1982). Ley 23 sobre derecho de autor. Gaceta Oficial.

Dalí, S. (2014). Itislove-Intense. Recuperado el 16 de marzo de 2014, de shop. salvador-dali.org: http://shop.salvador-dali.org/es/

Directiva 98/71/CE del Parlamento Europeo y del Consejo de 13 de octubre de 1998 sobre la protección jurídica de los dibujos y modelos, Directiva 98/71/ CE (Parlamento Europeo y Consejo 28 de 10 de 1998).

Duchamp, M. Fountain. Art Museum Image Gallery, Ipswich.

Ferrone, F., \& Hur, J. Prototype. Food \& Wine. FFerrone Design.

Ficsor, M. (2003). Guide to the Copyright and Related Rights Treaties Administered by WIPO and Glossary of Copyright and Related Rights Terms. Geneva: World Intellectual Property Organization.

Gaubiac, I. (enero de 1982). La teoría de la unidad del arte. Revista Internacional de Derecho de Autor RIDA, p. 42.

Hadid, Z., Icon Hill. Deezen Magazine. Leo Hillinger.

Interpretación prejudicial de los artículos 1, 13, 52 y 53 de la Decisión 351 de la Comisión del Acuerdo de Cartagena, 20-IP-2007 (Tribunal de Justicia de la Comunidad Andina 18 de 04 de 2007).

Interpretación prejudicial de los artículos 28 y 58 de la Decisión 351 de la Comisión del Acuerdo de Cartagena, 10-IP-1999 (Tribunal de Justicia de la Comunidad Andina 11 de junio de 1999).

Interpretación Prejudicial de los artículos 3, párrafo 12, y 4 literales g) y k) de la Decisión 351 del Acuerdo de Cartagena, 002-IP-2010 (Tribunal de Justicia de la Comunidad Andina 24 de 03 de 2010).

Interpretación prejudicial de los artículos 58, 59, 69 y 71 de la Decisión 344 de la Comisión del Acuerdo de Cartagena y Comisión de la Comunidad Andinade los artículos 258 y 259 de la Decisión 486 de la Comisión de la Comunidad Andina, 140-IP-2013 (Tribunal de Justicia de la Comunidad Andina 21 de agosto de 2013).

Interpretación Prejudicial, de oficio, de los artículos 113, 114, 115, 134, 136 literales a) y b), 154, 172, 190, 191, 192, 238, 243 y 244 de la Decisión 486 de la Comisión de la Comunidad Andina, 060-IP-2010 (Tribunal de Justicia de la Comunidad Andina 18 de agosto de 2010). 
Interpretación prejudicial, de oficio, de los artículos 113, 115, 122, 124, 258 y 259 de la Decisión 486 de la Comisión de la Comunidad Andina, 117-IP-2012 (Tribunal de Justicia de la Comunidad Andina 15 de marzo de 2013).

Israel, A. (29 de 01 de 2014). Botella de Vino Patio Seleccion. Recuperado el 08 de mayo de 2015, de https://www.flickr.com/photos/adan-israel-sumille: https://www.flickr.com/photos/adan-israel-sumiller/12211948604/ in/photolist-jB8qS1-ea4Pao-br7vhR-ea4G6h-7QYD5T-hqH7ZT-dERsNjoY1Vs9-cim7xN-96BXUN-5WWjUK-7R2X95-opiFjV-a7n2wG-9unrj6-bmiQzN-ebPG2E-kfaZ8g-bzBeFa-bmGmKw-8ipCaz-kunBVP-7EZkuk-9JquBp4eZ2Dw-aASC

Lipszyc, D. (1993). Derecho de autory derechos conexos (1 ed.). Buenos Aires: ZavalíaUnesco-CERLALC.

Miron Violettglas. (2013). Botella Vino 500 Ml. http://www.miron-glas.com/. Paises Bajos.

Organización Mundial de la Propiedad Intelectual, (2013). Organización Mundial de la Propiedad Intelectual. Recuperado el 08 de 01 de 2014, de www. wipo.int: http://www.wipo.int/wipolex/en/wipo_treaties/parties.jsp?treaty_ $\mathrm{id}=15$ Egroup_id $=1$

Organización Mundial de la Propiedad Intelectual OMPI, (11 a 15 de noviembre de 2002). Los Diseños Industriales y su Relación con las Obras de Arte Aplicadas y las Marcas Tridimensionales. Recuperado el 26 de marzo de 2011, de Organización Mundial de la Propiedad Intelectual: www.wipo.int

Otero Lastres, J. M. (2005). El grado de creatividad y de originalidad requerido al diseño artístico. Anuario Andino de Derechos Intelectuales, II(2), pp. 91-115.

Otero Lastres, J. M. (2005). Los requisitos de protección del diseño. Revista de Derecho, 6, pp. 195-220.

Otero Lastres, J. M. (2008). Reflexiones sobre el diseño industrial. Anuario de la Facultad de Derecho(1), pp. 217-235.

Picard, E. (1883). Embryologie juridique. Nouvelle classification des droits. (É. CLUNET, Ed.) Journal du Droit International Privé et de la Jurisprudence Compareé(10), pp. 565-585.

Real Academia Española. (2013). Diccionario de la Lengua Española. Recuperado el 29 de noviembre de 2013, de Real Academia Española: http://rae.es/recursos/diccionarios/drae

Reichman, J. (12 de 1983). Design Protection in Domestic and Foreign Copyright Law: From the Bern Revision of 1948 to the Copyright Act of 1976. Duke Law Journal, 1983(6), pp. 1143-1264. 
Revista Chilango. (7 de 12 de 2010). Chilango. Recuperado el 30 de 4 de 2015, de http://www.chilango.com/: http://www.chilango.com/restaurantes/ nota/2010/12/06/10-formas-de-botellas

Vega Barón, M. A. (s.f.). La Protección de los Diseños Industriales. Propiedad Intelectual, IV(6 y 7), 166-196.

Vega Jaramillo, A. (2010). Manual de Derecho de Autor. Bogotá D.C.: Dirección Nacional de Derecho de Autor. 